\title{
Design of a Compact Dual Band Microstrip Antenna for Ku-Band Applications
}

\author{
Ahmed Sayed \\ MSc Student at Ain Shams \\ University, Cairo, Egypt
}

\author{
R.S. Ghonam \\ Faculty of Engineering Girls' \\ CampusKing Abdul-Aziz \\ University, Jeddah, Saudi \\ Arabia (1) Electronics Research \\ Institute, Cairo, Egypt (2)
}

\author{
Abdelhalim Zekry \\ Professor, Department of \\ Electronics and Communication \\ Engineering, Faculty of \\ Engineering Ain Shams \\ University, Cairo, Egypt
}

\begin{abstract}
A new design of dual band compact microstrip antenna is proposed for Ku-band applications.Dual band is achieved using three pairs of thin slits from the sides of a rectangular patch and feeding with a microstrip feed line.The result shows that a return loss of $-32.9 \mathrm{~dB}$ is achieved at the first resonant frequency of $12.72 \mathrm{GHz}$, and $-14.4 \mathrm{~dB}$ is obtained at the second resonant frequency of $14.4 \mathrm{GHz}$ frequency with VSWR $\leq$ 2indicating improved matching conditions. The results ofsimulation are return loss, radiation pattern, VSWR, and band widtharepresented. The design is performed by using Ready-madeSoftware package Zeland- IE3D. The antenna is fabricated using thin film and photolithographic technique and measured using the Vector Network Analyzer. The final result shows that good agreement between the simulated and measured results.
\end{abstract}

\section{Keywords}

Microstrip antenna,Ku-band, Dual band

\section{INTRODUCTION}

Microstrip antennas have been one of the most innovative topics in antenna theory and design in recent years, and are increasingly finding application in a wide range of modern microwave systems [1]. Inherently they have numerous advantages like easy to fabricate using standard integrated circuit techniques, have low profile, are conformal, and can be easily integrated in arrays with electronic components. Nevertheless, microstrip antennas typically suffer from narrowband radiation (a few percent of center frequency), low gain, poor polarization purity, tolerance problem and limited power capacity. However, applications such as frequency tuning take advantage of the inherent narrow bandwidth of the microstrip antenna.

Systems such as satellites, global position system(GPS) are required to operate at two different frequenciesthat are very far from each other. Microstrip antennas canavoid the use of two different single band antennas. A variety of methods has been proposed to obtain dual frequency operation. Such as loading slits [2], using slots in the patch [3], [4], loading the patch with shorting pins [5], [6] and [7], using stacked patches [8], [9], [10] and[11] or using two feeding ports [12] are the most exploited ones. In addition, there are planar antennas of special geometries to achieve dual-bandoperation [13].

The Federal Communication Commission adopted a First Report and Order (First R\&O) to permit non-geostationary satellite orbit (NGSO) and fixed-satellite service (FSS) providersto operate in various segments of the Ku-band, and adopted rules and policies to govern these operations. NGSO FSS can provide a variety of new services to the public, such as high-speed Internet access, other types of high-speed data, video and telephony services. Because of its ability to serve large portions of the earth's surface, NGSO FSS can bring advanced services to rural areas. The Commission also adopted technical criteria so that NGSO FSS operations can share spectrum with incumbent services on a co-primary basis without causing unacceptable interference to them andwithout unduly constraining future growth of incumbent services or NGSO FSS system flexibility [14].

In this paper, a simple new compact design of single layer single patch element with microstrip feed line is proposed for dual frequency operation in Ku-band. The design and optimization resulted in a downlink frequency of $12.72 \mathrm{GHz}$ and uplink frequency of $14.4 \mathrm{GHz}$. The most obvious application in the Ku-band is aircraft, spacecraft and satellite based communication system.

\section{COMPACT DUAL BAND MICROSTRIP ANTENNA DESIGN FOR KU-BAND APPLICATIONS}

The dual frequency operation of microstrip antennas has been studied by a number of researchers using stacked patches with two separate feeds for each frequency band and polarization. In these structures, a combination of two different feeds is observed. These feeds are composed of two separate microstrip lines [15], two apertures [16], one via and onemicrostrip [17], two separate probes [18], and one microstrip and one aperture [19]. Other designs with a single electromagnetically coupled feed are also available [20], [21]. In general, stacked patches suffer from disadvantages such as thick substrate, difficult manufacturing, and high cost. On the other hand, using single feed antennas can reduce the complexity and the cost of the receiver front-end.

The geometry of the proposed microstrip antenna was modeled using the classical equations [22]:

$$
\begin{aligned}
& W=\left(\frac{C}{2 f_{0}}\right) \sqrt{\frac{\varepsilon_{r}+1}{2}} \\
& L=\left(\frac{C}{2 f_{0} \sqrt{\varepsilon_{e}}}\right)-2 \Delta l \\
& \varepsilon_{e}=\frac{\varepsilon_{r}+1}{2}+\frac{\varepsilon_{r}+1}{2} \sqrt{\left(1+\frac{10 h}{W}\right)}
\end{aligned}
$$




$$
\Delta l=0.412 h\left(\frac{\left(\varepsilon_{r}+0.3\right)\left(\frac{W}{h}+0.264\right)}{\left(\varepsilon_{e}-0.258\right)\left(\frac{w}{h}+0.8\right)}\right)
$$

Where $\mathrm{W}$ is the width of the patch, $\mathrm{L}$ is the length of the patch, $\Delta \mathrm{l}$ is the additional length on each end due to thefringing field along the widths, $\varepsilon_{\mathrm{r}}$ is the dielectric constant of the substrate, $\varepsilon_{\mathrm{e}} \mathrm{is}$ the effective dielectric constant, $\mathrm{c}$ isthe speed of light in a vacuum, $f_{o}$ is the target frequency and $h$ is the thickness of the substrate.

The antenna is initially designed to operate in dual frequency at Ku-band based on the above equations and consequently optimized to obtain the most preferable size of the patch using full wave method of momentof Zeland-IE3D electromagnetic simulator.

The geometry of the proposed antennaisshown in Figure 1.We use the rectangular shape dueto its compactness and small size. The area of the proposedshape equals $(5.7 * 7.96) \mathrm{mm}^{2}$ which is small compared to the conventional microstripantenna. The proposed antenna is constructed fromRogers RT/Duroid 6010substrate material withdielectric constant $(\varepsilon \mathrm{r}=10.2)$, substrate height $(\mathrm{h}=1.9 \mathrm{~mm})$, losstangent $(\tan \delta=0.023)$. The patch is fed from the down side by a $1.77 \mathrm{~mm}$ wide and $2.21 \mathrm{~mm}$ long microstrip feed line.

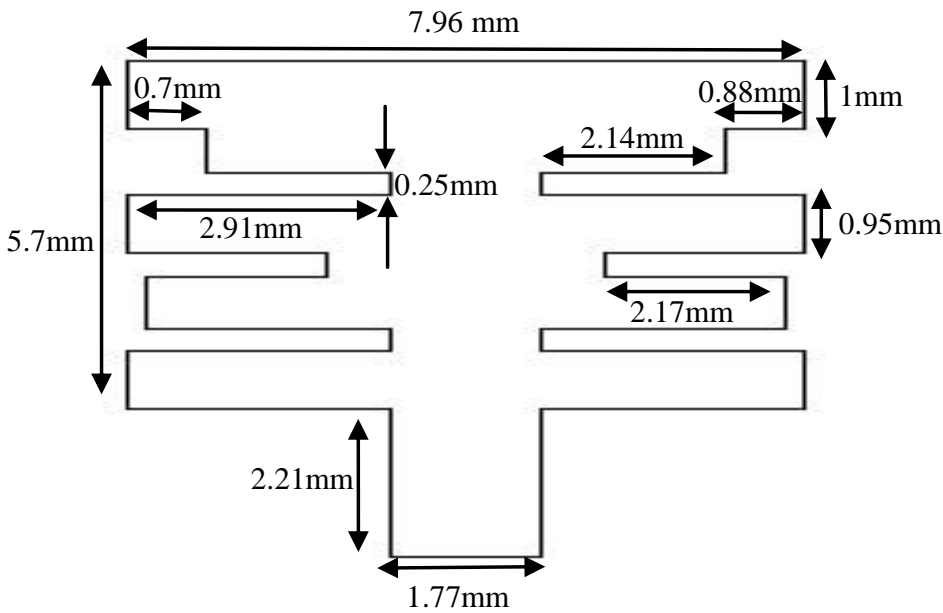

Fig 1:Antenna geometry of the microstrip antenna.

The radiating patch is basically a rectangular structure with three pair of slits with different lengths. The antenna is designed to match to $50 \Omega$, and an infinite conducting ground plane is assumed in the simulation.

\section{RESULTS AND DISCUSSION}

The antenna performance was studied by the commercially available simulation software Zeland IE3D. The simulated return loss of the proposed antenna is depicted in Figure2.This Figureshows that the patch has two resonance frequencies of $12.72 \mathrm{GHz}$ and $14.4 \mathrm{GHz}$ having reflection coefficients of$32.9 \mathrm{~dB}$ and $-14.4 \mathrm{~dB}$, respectively. The $-10 \mathrm{dBbandwidth}$ is $680 \mathrm{MHz}$ at the lower resonance frequency and $990 \mathrm{MHzat}$ the higher resonance frequency.

The value of VSWR is less than 2at both resonance frequencies indicating acceptable matching conditions of the design system.

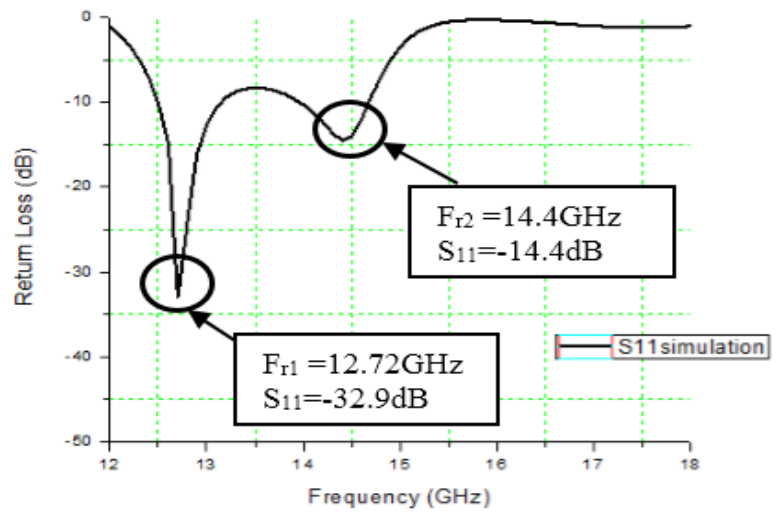

Fig2:Simulated return loss of the proposed antenna.

The radiation patterns of the proposed antenna at resonant Frequencies $12.72 \mathrm{GHz}$ and $14.4 \mathrm{GHz}$ in E-plane are shown in Figure 3"a" and"b".It can be clearly seen that the designedantenna produces broadside and almost symmetrical radiation pattern; therefore, a large amount of stable power is in the directionof the broadside beam.

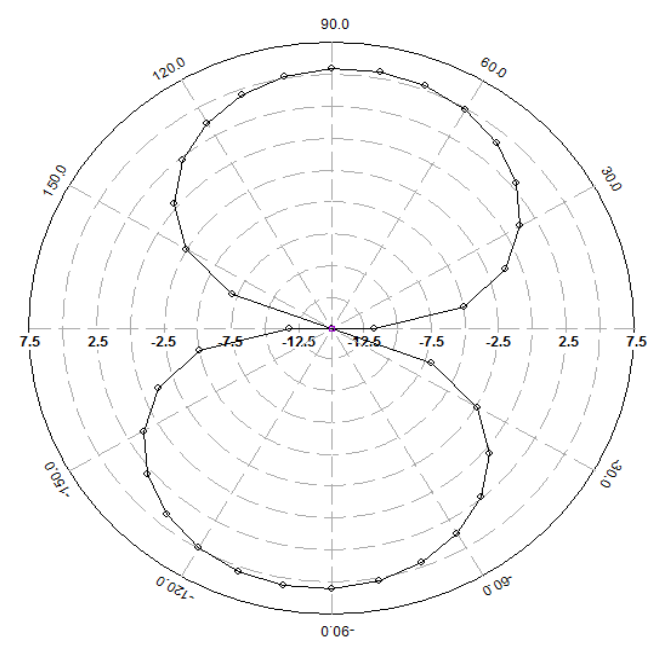

Fig3.a: The Simulated radiation pattern of the proposed antenna at $12.72 \mathrm{GHz}$

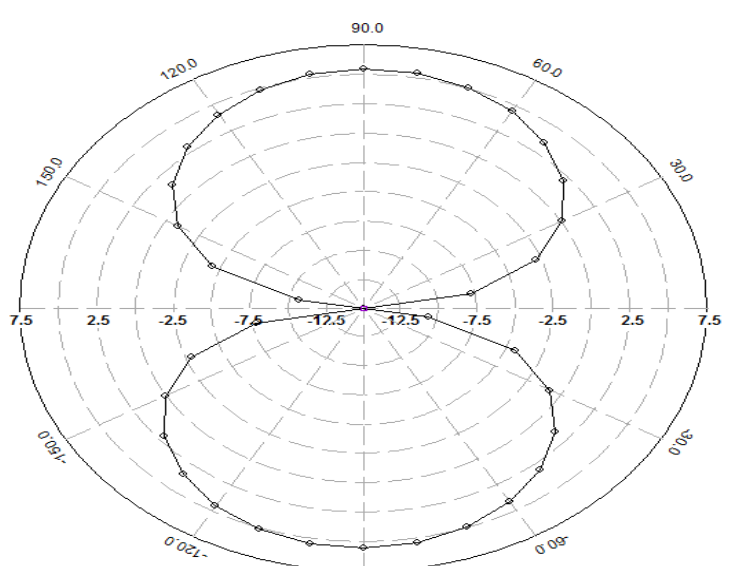

Fig3.b:The Simulated radiation pattern of the proposed antenna at $14.4 \mathrm{GHz}$

To verify the simulation results we fabricated specimens of the proposed antenna structure and a photograph of such Specimens is shown in Figure 4. 


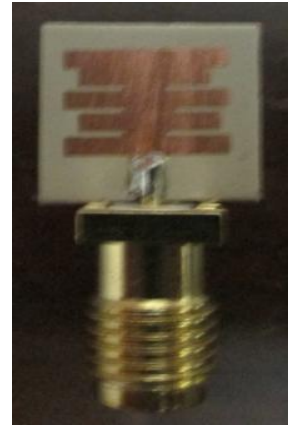

Fig4: The fabricated specimen of the proposed antenna.

The measuredreturn loss of the proposed antenna is shown in Figure 5. We have achieved a $399 \mathrm{MHz}$ bandwidth, ranging from $12.503 \mathrm{GHz}$ to $12.902 \mathrm{GHz}$ on the 1 st resonance and $300 \mathrm{MHz}$ ranging from $14.102 \mathrm{GHz}$ to $14.402 \mathrm{GHz}$ on the 2 nd resonance.

The simulated and measured return losses of the proposed antenna are shown in Figure 6.The resonant frequencies are shifted from $12.72 \mathrm{GHz}$ to $12.7 \mathrm{GHz}$ on the lower band andfrom $14.4 \mathrm{GHz}$ to $14.2 \mathrm{GHz}$ on the upper band. Deviation between the simulation and measurement may be attributed to the excitation of surface waves that occurs in the substrate layer as well as tothe manufacturing defects.

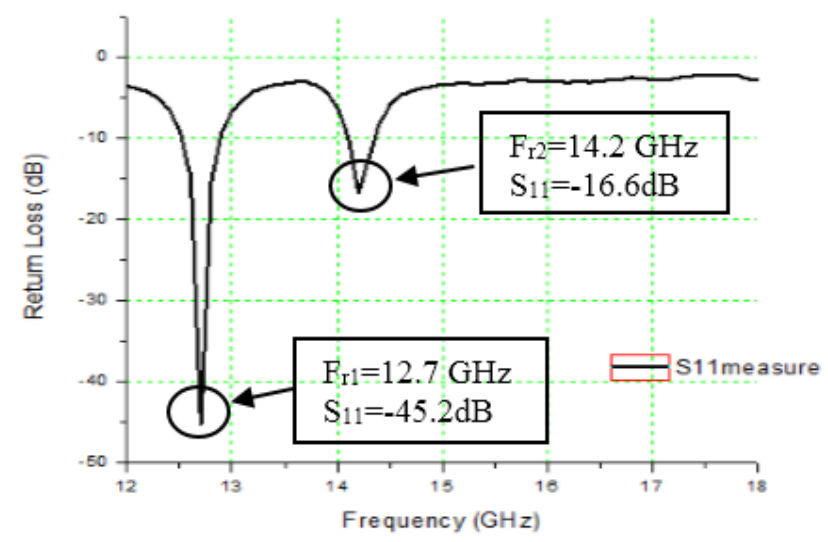

Fig5:Measured return loss of the proposed antenna.

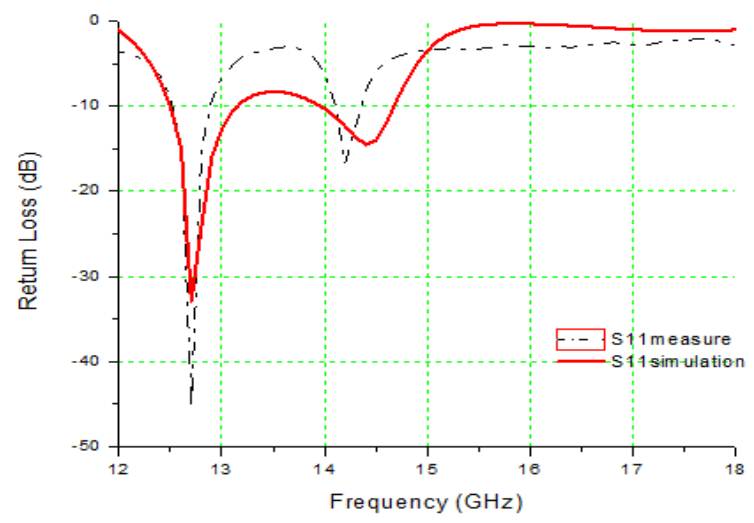

Fig6: Simulated and measured return losses of the proposed antenna.

The major measured results of the antenna are also given in table 1 for sake of comparison with the simulated results.Satisfactory agreement was found between the measured and simulated results except for small some differences.The differences between thesimulated and measured results arebecause of the presence of additional parasitic capacitances which are not taken intoconsideration in simulation. There are also fabrication tolerances in the dimensions of the printed antenna.

Table 1.Summary of the antenna results

\begin{tabular}{|c|c|c|c|c|c|c|c|}
\hline \multicolumn{2}{|c|}{ Fr (GHz) } & \multicolumn{2}{c|}{ S $_{11}(\mathbf{d B})$} & \multicolumn{2}{c|}{$\begin{array}{c}10 \text { dB } \\
\text { BW(MHz) }\end{array}$} & \multicolumn{2}{c|}{ VSWR } \\
\hline Simu. & Meas & Simu. & Meas & Simu. & Meas & Simu & Meas \\
\hline 12.72 & 12.7 & -32.9 & -45.2 & 680 & 399 & 1.06 & 1.02 \\
\hline 14.4 & 14.2 & -14.4 & -16.6 & 990 & 300 & 1.47 & 1.61 \\
\hline
\end{tabular}

\section{CONCLUSION}

In this paper, a new patch configuration to execute dualfrequency operation at Ku-band with three pairs of slitsusing microstrip feed line have been proposed. The designand simulation has been carried out by the use of IE3D-Full-Wave EM Simulation Package. The fabrication of the proposed antenna is performed with slits and a Rogers RT/Duroid 6010dielectric substrate and is excited by a $50 \Omega$ microstriptransmission line.Good results have been found at dual frequencies $12.72 \mathrm{GHz}$ as downlink and $14.4 \mathrm{GHz}$ as uplink.Satisfactory agreement between the simulated and measured resultswas found. This antenna is nominated to be applied for the satelliteapplications which requiresimultaneous transmit/receive functionality at widelyseparated frequency bands.

\section{FUTURE WORK}

The isolation between the two bands must be improved. The deviation between the simulation and measurement must be reduced. Measuring the radiation pattern of the fabricated antenna and compare it with simulation results. Multiple resonators antennas and wider bandwidth can be realized.

\section{REFERENCES}

[1] David M. Pozar, January 1992, "Microstrip Antennas", Proceedings of IEEE, Vol. 80, No. 1.

[2] IndraSurjati, 3 - 5October 2005, "Dual Frequency Operation Triangular Microstrip Antenna Using A Pair Of Slit”, 2005 Asia-Pacific Conference on Communications, Perth, Western Australia, pp. 125-127.

[3] S. Maci, G. B. Gentili, P. Piazzesi, and C. Salvador, Jun 1995,"Dual band slot loaded patch antenna," Proc. Inst. Elect. Eng. Microw. Antennas Propag. vol. 142, pp. 225232.

[4] B. F.Wang and Y. T. Lo, Sep. 1984,"Microstrip antennas for dual-frequency operation," IEEE Trans. Antennas Propag. vol. 32, pp. 938-943.

[5] C. L. Tang, H. T. Chen, and K. L. Wong, Jun 1997,"Small circular microstrip antenna with dualfrequency operation," IEEE Electron. Lett, vol.33, no. 13, pp. 1112-1113.

[6] K. L. Wong and W. S. Chen, Apr. 1997,“Compact microstrip antenna with dual frequency operation," IEEE Electron. Lett, vol. 33, no. 8, pp. 646-647.

[7] S. C. Pan and K. L. Wand, Dec. 1997,"Dual frequency triangular microstrip antenna with shorting pin," IEEE Trans. Antennas Propag., vol. 45, pp. 1889-1891. 
[8] L. Zaid, G. Kossiavas, J. Y.Dauvignac, J. Cazajous, and A.Papiemik, Apr. 1999,"Dual-frequency and broadband antennas with stacked quarter wavelength elements," IEEE Trans. Antennas Propag., vol.47, no. 4, pp. 654660.

[9] J. S. Dahele, K. F. Lee, and D. P. Wong, Nov. 1987,"Dual frequency stacked annular ring microstrip antenna," IEEE Trans. Antennas Propag.,vol. 35, no. 11, pp. 1281-1285.

[10] F. Croq and D. M. Pozar, Nov. 1992,"Multifrequency operation on microstripantennas using aperture coupled parallel resonators," IEEE Trans.Antennas Propag., vol. 40, no. 11, pp. 1367-1374.

[11] J. Wang, R. Fralich, C. Wu, and J. Litva, Dec. 1990,"Multifunctional aperture coupled stack patch antenna," IEEE Electron. Lett., vol. 26, no. 25, pp. $2067-$ 2068 .

[12] J. F. Zurcher, A. Skrivervik, O. Staub, and S. Vaccaro, Oct. 1998, “A compact dual-port dual-frequency printed antenna with high decoupling," Microw Opt. Technol. Lett., vol. 19, pp. 131-137.

[13] H. Choo and H. Ling, Jun. 2003,"Design of broadband and dual-bandmicrostrip antennas on a high-dielectric substrate using a genetic algorithm," in Proc. Inst. Elect. Eng. Microw. Antennas Propag, vol. 15, pp. 137-142.

[14] Action by the Commission November 29, 2000, by Federal Report and Order/Further Notice of Proposed Rulemaking (FCC 00-418). Chairman Kennard, Commissioners Ness, Powell and Tristani with Commissioner Fuchtgott-Roth.

[15] H. S. Noh, J. S. Yun, J. M. Kim, and S. I. Jeon, Jun. 2004,"Microstrip patch array antenna with high gain and wideband for Tx/Rx dual operation at Ku-band," in Proc. IEEE Antennas Propagation Society Int. Symp. Digest, vol. 3, pp. 2480-2483.

[16] N. C. Karmakar, S. Padhi, and S. Aditya, Dec. 2000, "Development of a portable VSAT antenna array for satellite communications," in Proc. IEEE AsiaPacific Microw. Conf., pp. 34-37.

[17] Y. Kim, W. Yun, and Y. Yoon, Aug. 1999,“Dualfrequency and dual polarization wideband microstrip antenna," IEEE Electron. Lett.,vol. 35, no. 17, pp. 1399 1400 .

[18] K. S. Kona and Y. Rahmat-Samii, Jun. 2003,"Design and analysis of a novel probe-feeding method for stacked microstrip patch antennas," in IEEE Antennas Propagation Society Int. Symp. Digest,vol. 1, pp. 425428.

[19] J. S. Yun, H. S. Noh, S. I. Jeon, and C. J. Kim, Aug. 2003, "Design and analysis of $\mathrm{Tx} / \mathrm{Rx}$ dual microstrip antenna using FDTD at Kuband," IEEE Electron. Lett., vol. 39, no. 17, pp. 1228-1230.

[20] S. V. Shynu, R. K. Raj, A. R. Chandran, C. K. Aanandan, P. Mohanan, and K. Vasudevan, Jun. 2004,"Single-feed dual-frequency dual polarized microstrip antenna with hexagonal slot," in IEEE Antennas Propagation Society Int. Symp. Digest, vol. 4, pp. 4380-4383.

[21] M. Paulson, S. O. Kundukulam, C. K. Aanandan, and P. Mohanan, Jun 2002, "Compact arrow shaped antenna with embedded rectangular slot for dual frequency dual polarisation operation," in 2002 IEEE Antennas Propagat. Society Int. Symp. Digest, vol. 2, pp.56-59.

[22] J.J.Bahl, P.Bhartia, 1980, Microstrip Antennas, Artech House. 